\title{
TU/e EmonOWEN

\section{Effect of inclination angle on hooked end steel fiber pullout behavior in ultra-high performance concrete}

\section{Citation for published version (APA):}

Cao, Y. Y. Y., \& Yu, Q. L. (2018). Effect of inclination angle on hooked end steel fiber pullout behavior in ultrahigh performance concrete. Composite Structures, 201, 151-160.

https://doi.org/10.1016/j.compstruct.2018.06.029

DOI:

10.1016/j.compstruct.2018.06.029

Document status and date:

Published: 01/10/2018

\section{Document Version:}

Accepted manuscript including changes made at the peer-review stage

\section{Please check the document version of this publication:}

- A submitted manuscript is the version of the article upon submission and before peer-review. There can be important differences between the submitted version and the official published version of record. People interested in the research are advised to contact the author for the final version of the publication, or visit the $\mathrm{DOI}$ to the publisher's website.

- The final author version and the galley proof are versions of the publication after peer review.

- The final published version features the final layout of the paper including the volume, issue and page numbers.

Link to publication

\section{General rights}

Copyright and moral rights for the publications made accessible in the public portal are retained by the authors and/or other copyright owners and it is a condition of accessing publications that users recognise and abide by the legal requirements associated with these rights.

- Users may download and print one copy of any publication from the public portal for the purpose of private study or research.

- You may not further distribute the material or use it for any profit-making activity or commercial gain

- You may freely distribute the URL identifying the publication in the public portal.

If the publication is distributed under the terms of Article 25fa of the Dutch Copyright Act, indicated by the "Taverne" license above, please follow below link for the End User Agreement:

www.tue.nl/taverne

Take down policy

If you believe that this document breaches copyright please contact us at:

openaccess@tue.nl

providing details and we will investigate your claim. 
3 Effect of inclination angle on hooked end steel fiber pullout behavior in ultra-high performance concrete

Y.Y.Y CAO and Q.L. YU *

Department of the Built Environment

Email: q.yu@bwk.tue.nl

28 *: to whom correspondence should be addressed

29 


\section{Abstract:}

33 The bond relationship between the concrete matrix and steel fiber is a significant factor that affects

34 the performance of ultra-high performance fiber reinforced concrete (UHPFRC). In the present 35 research, pullout performances of hooked end fibers embedded in ultra-high performance concrete 36 matrix under various inclination angles are systematically investigated, with special attention on 37 fiber dimension and embedded length. Pullout load-slip curves are obtained and experimental 38 observations including complete fiber pull-out, fiber rupture and matrix failure are analyzed in 39 detail. The effects of the pullout angle are then studied quantitatively by parameter calculations 40 and mechanism analysis. A new analytical model for evaluating the snubbing and spalling effects 41 of the hooked end steel fiber is proposed and validated. It is shown that the influences of the 42 inclination angle on the peak pullout load vary with different fiber types, embedded lengths and 43 fiber diameters, which are also associated with the occurrences of the fiber rupture and the matrix 44 failure. In addition, optical microscope and scanning electron microscopy observations at 45 mesoscale are performed to further analyze the effects of orientation angle.

47 Keywords: single-fiber pullout; hooked end fiber; ultra-high performance concrete; inclination 48 angle; parametric evaluation, pullout mechanism. 


\section{$51 \quad 1 \quad$ Introduction}

52 Ultra-High Performance Fiber Reinforced Concrete (UHPFRC) is a construction material 53 characterized by its very high compressive strength, excellent durability, energy absorption 54 capacity and damage tolerance [1-6]. Fibers play an important role in UHPFRC. The incorporation 55 of fibers to ultra-high performance concrete (UHPC) matrix significantly improves its tensile 56 strength, post-cracking ductility and energy absorption capacity, as well as reduces crack width 57 and crack spacing [7-9]. In addition to the fiber content, individual pullout behavior of the activated 58 fibers crossing a crack is also a significantly influential factor that affects the performances of 59 UHPFRC composites.

60 As a foundation to analyze the fiber effects on cementitious composite and the fiber-matrix 61 bond relationship, fiber pullout test provides basic information and a comprehensive understanding 62 on the bond-slip characteristics, and thus enables further improvement on the fiber-matrix 63 interfacial properties $[10,11]$. The pullout behavior of a single steel fiber depends on many factors 64 [12], including the fiber geometry, orientation angle, embedded length, matrix quality, as well as 65 the pullout rate. A number of pullout tests about fiber embedded in normal concrete (NC) or high 66 strength concrete (HSC) have been performed, analytical and numerical models are also developed 67 to predict the pullout load-displacement relationship [13]. However, since matrix quality is one dominant factor that influences the pullout behavior, the performance of steel fibers embedded in UHPC matrix can differ remarkably with that in NC or HSC [10, 12, 14]. Fig. 1 plots the load-slip relationships of a smooth straight fiber pulled out from NC and UHPC matrix [14, 15]. Instead of

71 a sudden sharp drop after reaching the peak stress as observed in the case of NC (Fig. 1a), the 72 pullout stress of UHPC declined continuously until the end of the complete pullout process (Fig. 73 1b). As indicated by scanning electron microscope (SEM) images, the fiber-matrix interface zone 74 of the UHPC matrix is much denser than that of NC and HSC thanks to the usage of fine particles 75 and the improved filling effect in UHPC $[10,16]$. The high particle packing density of UHPC 76 matrix creates a superior bond between the fiber and the matrix, leading to a slip-hardening pullout 77 phenomenon that is not encountered in the NC matrix [10]. The enhanced strength of the matrix 78 also provides a higher resistance to the matrix spalling, hence increasing the fiber's capabilities in 79 the pullout resistance and energy absorption [17]. In addition, as the water/binder (W/B) ratio is 
reduced in UHPC, its shrinkage magnitude is enhanced. It should be noted that concrete shrinkage

81 has both positive and negative effects on the interfacial bond: (1) the higher radial confinement

82 pressure generated due to shrinkage benefits the enhancement of friction bond; (2) shrinkage stress

83 can also result in matrix cracking, which weakens the fiber-matrix bond. By testing the influence

84 of shrinkage reducing agent on the pullout performance of UHPC, [15] confirms that the shrinkage

85 in UHPC has a more prominent effect on increasing the interface bond compared to the decrease 86 caused by cracking.

(a)

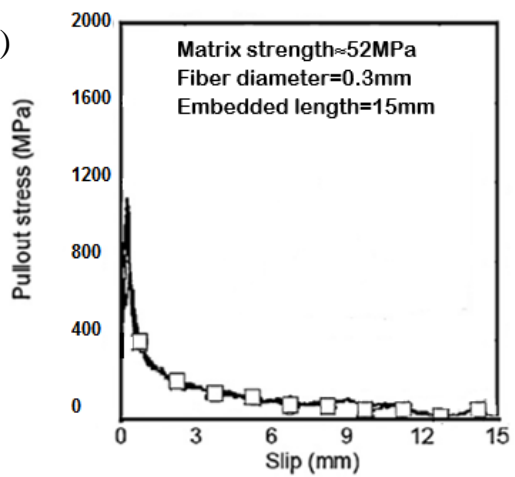

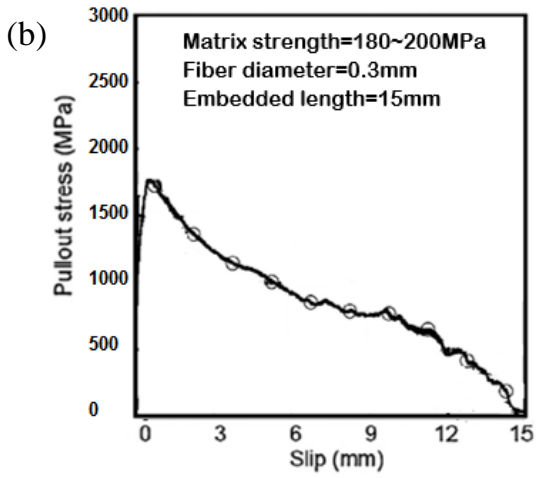

Fig.1 Pullout stress versus slip of smooth straight fibers from: (a) NC [14]; (b) UHPC [15].

Being a relatively new material [1-3], UHPFRC has been increasingly utilized in modern constructions in recent years. Nonetheless, studies about the pullout characterization of UHPFRC are still insufficient, especially compared with the investigations concerning NC and HSC [10, 14].

92 Among the limited studies, Wille and Naaman [10, 18-20] conducted a series of single fiber pullout

93 tests of steel fibers embedded in UHPC matrix. The research reveals that the improvement in the 94 particle packing of UHPC contributes to an enhanced bond slip hardening behavior. By comparing 95 the pullout responses of the straight and the deformed fibers, they found that the complementary 96 mechanical bond of the deformed fiber increases the equivalent bond strength. However, these 97 enhanced bond properties also lead to the breakage of the fiber during the pullout process. Abdallah 98 et al. [11] analyzed the fiber-matrix interfacial properties of hooked end steel fibers embedded in 99 UHPC matrixes with various fiber embedded lengths and W/B ratios. Their results present that the maximum pullout load increases as the W/B ratio decreases, while the embedded length has no 101 appreciable effect. Yoo et al. [16, 21] investigated the influences of fiber type and matrix strength 102 
103 pullout behavior is improved with the enhancement of the matrix strength, and the hooked end 104 fibers exhibit higher bond strength and pullout work than the straight fibers.

105 In UHPFRC, fibers are usually randomly distributed. Fibers under different inclination angles 106 provide distinct contributions at a given crack width [22]. On the one hand, fiber inclination can 107 lead to increases in the bridging force and the pullout work [12, 23]. On the other hand, it also 108 generates higher stresses in the fiber and matrix, and thus a higher fiber and/or concrete rupture 109 potential [12, 23-25]. The analytical model developed by Zhang and Li [24] for studying the effects 110 of inclination angle exhibits that fiber rupture load is significantly reduced for inclined fibers than 111 for aligned ones, and this load decreases with the increment of the matrix modulus. It can be 112 inferenced from their research that steel fibers embedded in a high-modulus UHPC matrix with 113 inclination angles other than $0^{\circ}$ may have higher chances to break during the pullout processes. 114 This further indicates the importance of studying the effects of inclination angle on the pullout 115 behavior from UHPC. Nonetheless, most of the current pullout investigations regarding UHPC 116 focus on aligned fibers while research concerning inclined fibers is inadequate. Lee et al. [26] 117 conducted pullout tests of straight steel fibers embedded in UHPFRC with orientation angles of 0 118 to $60^{\circ}$, the largest peak load is observed at an angle between 30 and $45^{\circ}$. Xu et al. [27] studied the 119 pullout behaviors of straight steel fibers from UHPC and analyzed the influences of inclination 120 angles on the loading rate sensitivity. It is found in their research that an inclination angle of $20^{\circ}$ 121 leads to a more promising rate effect. More recently, Tai and El-Tawil [28] investigated the pullout 122 behaviors of inclined deformed steel fibers in UHPC under different loading rates. According to 123 their study, pullout resistances are sensitive to both inclination angle and loading rate. However, 124 their study focused more on the loading rate effect rather than the influence of the pullout angle.

125 Since traditional UHPFRC is usually reinforced with straight steel fibers in order to match the 126 fine aggregates in the UHPC matrix, the objectives of most pullout research about UHPC are 127 usually smooth straight fibers [29]. However, recent researches show that concrete containing 128 appropriate type and content of coarse aggregate possesses some advantages on e.g. economic 129 efficiency, shrinkage control [30] and impact resistance improvement [31, 32]. For these UHPFRC 130 with coarse aggregates, e.g. large basalt aggregates, hooked end steel fiber is a more appropriate 131 and efficient reinforcement considering its stronger crack-bridging effect [33]. In addition, hooked 132 end steel fibers are increasingly used in UHPFRC to enhance the interfacial bond [1, 34-39]. Some 133 investigations confirm that UHPFRC composite reinforced with deformed steel fiber, e.g. hooked 
134 end fiber or twisted fiber, provides a superior performance with respect to post cracking strength, 135 strain capacity and multiple cracking behavior than its counterpart with straight fiber [33, 37-39]. 136 These tendencies make understanding the pullout behavior of hooked end fibers embedded in 137 UHPC matrix of great significance. To investigate the pullout responses of inclined fibers, 138 analytical models for evaluating the combined effects of snubbing and matrix spalling are of great 139 importance [26]. Despite the models for straight steel fibers [17, 26, 28], there is still a lack of 140 theoretical model for hooked end fibers. Furthermore, the insufficiency of researches concerning 141 the performances of inclined hooked end fibers pulled out from UHPC matrix also highlights the 142 significance of conducting systematical investigations.

143 Accordingly, the present study aims to investigate the pullout performances of hooked end steel 144 fibers embedded in an UHPC matrix, with the effort on the effects of inclination angles. Single 145 fiber pullout tests are performed, supported by mechanical parameter calculations. Based on 146 equations for straight fiber pull-out, a new theoretical model for hooked end fibers to evaluate the 147 snubbing and matrix spalling effects is developed. Furthermore, mesoscale observations of the 148 investigated materials are carried out employing optical microscope and SEM. The results obtained 149 from this study provide fundamental insights on the effect of hooked end steel fibers for improving 150 UHPFRC properties and for a more efficient utilization of fibers in UHPFRC. 


\section{Single fiber pullout experiments}

\section{$153 \quad 2.1 \quad$ Steel fibers}

154 As shown in Fig. 2, two types of hooked end steel fibers are used in the single fiber pullout tests 155 in the present study. One is a commercially available steel fiber, i.e. Dramix RC-80/30-BP fiber, 156 and the other one is a one-hooked-end steel fiber cut from Dramix 5D fiber. The basic geometry 157 and mechanical parameters of the fibers are given in Table 1. The identification is defined as 158 follows: the first letter indicate the fiber is hooked end steel fiber, the first number denotes the 159 fiber diameter in $\mathrm{mm}$, and the last number indicates the fiber embedded length in $\mathrm{mm}$. For example, $160 \mathrm{H}-0.38-10$ is a hooked end fiber with a diameter of $0.38 \mathrm{~mm}$ embedded with $10 \mathrm{~mm}$.

161

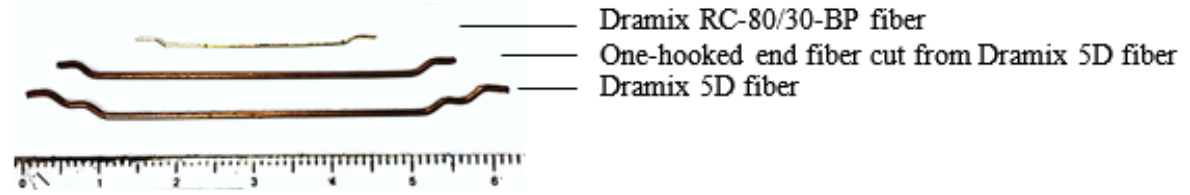

Fig. 2 Hooked end steel fibers in the single fiber pullout tests

Table 1 Specifications of fibers

\begin{tabular}{cccc}
\hline Fiber type & Dramix RC-80/30-BP fiber & One-hooked end fiber cut from Dramix 5D fiber \\
\hline Identification & $\mathrm{H}-0.38-10$ & $\mathrm{H}-0.9-10$ & $\mathrm{H}-0.9-15$ \\
Fiber diameter $d(\mathrm{~mm})$ & 0.38 & 0.90 & 0.90 \\
Fiber length $l_{\mathrm{f}}(\mathrm{mm})$ & 30 & 60 & 60 \\
Embedded length $l_{\mathrm{e}}(\mathrm{mm})$ & 10 & 10 & 15 \\
Tensile strength $f_{\mathrm{t}}(\mathrm{MPa})$ & 2600 & 2600 & 2600 \\
\hline
\end{tabular}

\subsection{UHPC matrix}

The UHPC matrix for the pullout test is based on the recipe described in $\mathrm{Li}$ et al. [40]. The raw materials used are Portland Cement CEM I 52.5 R (PC), micro-silica (mS), limestone powder (LP), sand 0-2 (S), basalts aggregate 1-3 (BA), water (W), and PCE-type superplasticizer (SP). The particle size distributions of the materials are measured by sieve and laser diffraction analyses (Malvern Mastersizer 2000®), as shown in Fig. 3. Tables 2 and 3 give the specific densities and proportions of the materials used in the UHPC matrix, respectively [40]. The average compressive strength $f_{\mathrm{c}}$ of the UHPC measured at 28 days is $156 \mathrm{MPa}$. More detailed information about the mix design, mechanical properties and followability of the UHPC matrix can be found in [40]. 
174

175

176

177

178

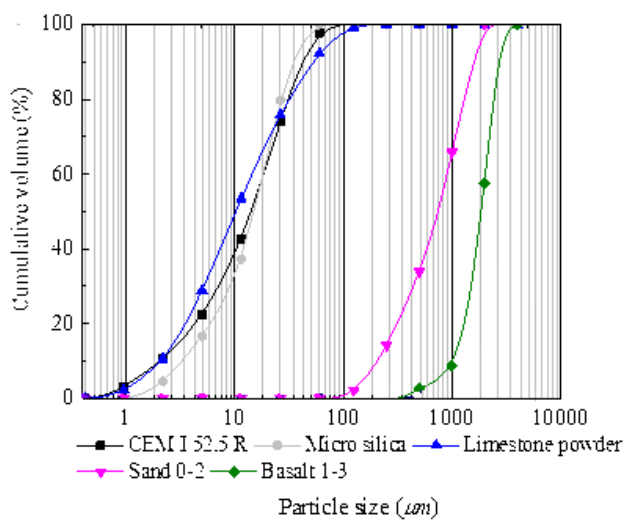

Fig.3 The particle size distribution of raw materials [40]

Table 2 Specific densities of raw materials $\left(\mathrm{g} / \mathrm{cm}^{3}\right)[40]$

\begin{tabular}{cccccccc}
\hline Materials & PC & $\mathrm{mS}$ & LP & S & BA & W & SP \\
\hline Specific density & 3.15 & 2.32 & 2.71 & 2.72 & 3.05 & 1.00 & 1.07
\end{tabular}

Table 3 Recipe of UHPC matrix $\left(\mathrm{kg} / \mathrm{m}^{3}\right)$

\begin{tabular}{lccccccc}
\hline Materials & PC & $\mathrm{mS}$ & LP & S & BA & W & SP \\
\hline Quantity & 675 & 45 & 180 & 864.5 & 576.3 & 180 & 10.8
\end{tabular}

\subsection{Casting of specimens}

The following mixing procedure is adopted for the preparation of the UHPC matrix: dry mixing for 2 min with all powder, sand and basalt aggregates; adding 75\% water and mixing for 2 min; sequentially adding the remaining water with the superplasticizer incorporated and mixing for another $2 \mathrm{~min}$ at a low speed and then $4 \mathrm{~min}$ at a high speed. The mixing procedure is conducted at room temperature of about $20 \pm 1{ }^{\circ} \mathrm{C}$. After mixing, the self-consolidating UHPC is poured without vibration into a half dog-bone shape mold, in which a single hooked end fiber is carefully placed and held by hard foams with the desired embedded length and inclination angle (Fig. 4a and b). The inclinations applied in this study are $0^{\circ}, 10^{\circ}, 20^{\circ}$ and $30^{\circ}$. At least five specimens are tested in each inclination category. After casting, the specimens are covered with plastic sheets to prevent moisture evaporation and stored at room temperature for 24 hours. Then they are demolded and cured in water under room temperature for an additional 27 days. All specimens are tested in surface dry condition after the age of 28 days. 


\subsection{Pullout test setup and procedure}

194 The pullout test is conducted using an Instron 5967 universal testing machine (Fig. 4c). A round 195 concrete grip is applied to hold the half dog-bone shaped specimen in order to reduce the 196 confinement effect of the grip on the concrete. The fiber grip is also specially designed such that 197 the free end of the fiber is tightly held without significant slippery in the grip. By assuming that 198 the elastic deformation of the steel fiber and the grips are small enough [16, 19, 27, 32], the fiber 199 slip is measured according to the vertical movement of the grip system. The pullout load is 200 measured by a load cell with a capacity of $30 \mathrm{kN}$. The tests are performed under the displacement 201 control and the pullout rate adopted is $0.5 \mathrm{~mm} / \mathrm{min}$.

(a)

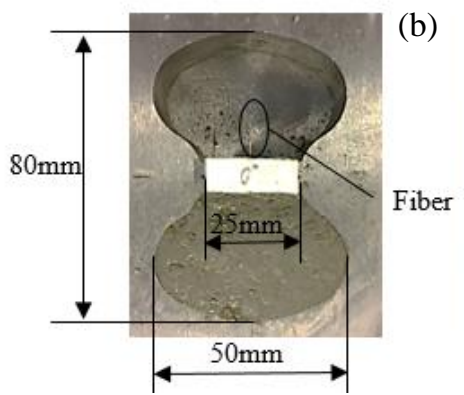

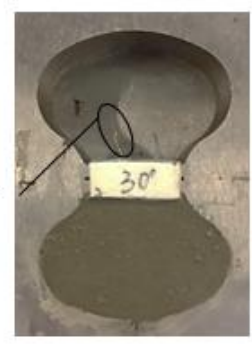

(c)

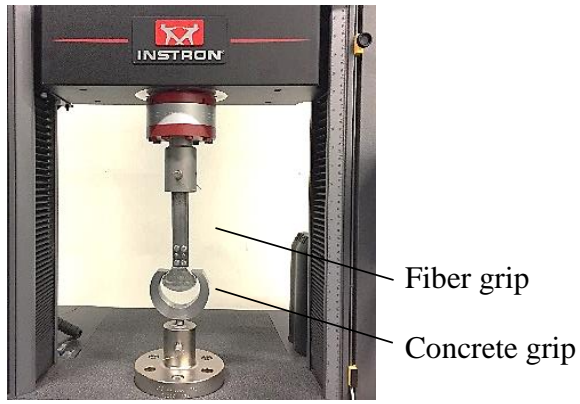

Fig.4 Pullout specimens and test setup: (a) $0{ }^{\circ}$ specimen; (b) $30^{\circ}$ specimen; (c) Instron testing machine 


\section{Pullout responses}

206 During the pullout tests three distinct responses are observed, namely complete fiber pullout, 207 fiber rupture and matrix failure. The first one is usually observed under small pullout angles for 208 the three categories. On the contrary, the second and third ones occur more frequently under larger 209 inclination angles for the $\mathrm{H}-0.38-10$ and $\mathrm{H}-0.9-10$ fibers, respectively.

$210 \quad 3.1 \quad$ Complete fiber pullout

211 To analyze the complete pullout behavior, typical pullout load-slip relationships for the H-0.38-

21210 fiber under different angles are plotted in Fig. 5. The curves for each inclination angle are the 213 average values of at least 5 specimens except for the $30^{\circ}$ category, which is averaged from 3 214 specimens due to the fiber rupture of the other specimens (Table 4). As can be observed in Fig. 5, 215 these curves have resemble shapes, suggesting a good alignment of the testing as well as a similar 216 pullout process under different inclination angles. In the initial elastic stage of the pullout test, the 217 response is almost linear until the initiation of debonding (point A), after which fiber-matrix 218 interface failure begins. The pullout load then increases at a slower rate. The contribution of the 219 hook is activated after the complete debonding of the fiber and it reaches its maximum at the peak 220 point B. Through the pullout process in this stage, the hook part of the steel fiber undergoes large 221 deformations, i.e. plastic hinges are formed in the two curved sections of the fiber hook where 222 plastic bending occurs. In addition, the corresponding slip under point B increases with the 223 increase of the orientation angle. Subsequently, the ascending slope of the pullout load-slip curve 224 tends to be smaller under a larger angle. In the post-peak stage, the hook undergoes a straightening 225 procedure, during which the plastic hinges play an important role. The fluctuations of the curve 226 after point B are associated with the deformation of the hook. When the hook is fully straightened 227 and slips along the straight tunnel (point C), the plastic hinges are deactivated and fiber-matrix 228 friction becomes the dominant mechanism. The pullout load decreases gradually due to the reduction of the remained embedded length until the end of the pullout process (point D).

230 Fig. 5 also exhibits the effect of the orientation angle on the peak pullout load. The values under $2310^{\circ}$ and $10^{\circ}$ are close to each other and they are only slightly higher than those under $20^{\circ}$ and $30^{\circ}$.

232 This is primarily due to some small concrete pieces spalling off from the pullout surface at 20 and $23330^{\circ}$, resulting in a smaller embedded length of the steel fiber, thus a reduced pullout load. An 234 example of the matrix spalling zone on the pullout surface under $30^{\circ}$ is shown in Fig. 6a. The 
235 tendency in Fig. 5 is in accordance with the finding in [41] that the peak loads of the hooked end 236 fiber remained nearly unchanged under angles from 0 to $60^{\circ}$ when pulled out from a concrete with 237 the compressive strength of $85 \mathrm{MPa}$. Nonetheless, contradictory results can be found in other 238 literature. For example, Tai and El-Tawil [28] tested the pullout behavior of hooked end steel fiber 239 from UHPC $\left(f_{c}=184 \mathrm{MPa}\right)$ under 0 to $45^{\circ}$ and found that the peak pullout load was maximized at 240 approximately $30^{\circ}$. The difference may be ascribed to the following reasons. Firstly, the enhanced 241 strength of the matrix in [28] can lead to an improved frictional resistance between the fiber and 242 the matrix, generating a more remarkable snubbing effect that increases the peak pullout load with 243 the inclination angle [25]. Secondly, in their test the spalling of matrix is only observed under the 244 pullout angle of $45^{\circ}$, which means the resistance loss due to the reduced embedded length is only 245 occurred under $45^{\circ}$ rather than under 20 and $30^{\circ}$ as observed in this study.

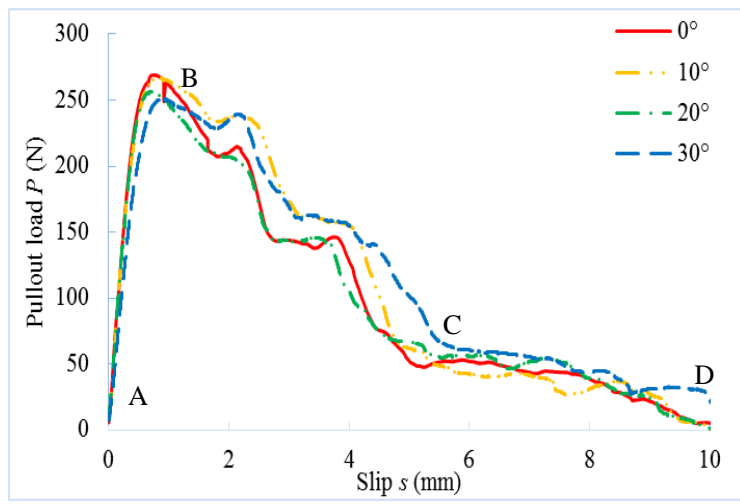

Fig.5 Pullout load-slip curves of H-0.38-10 fiber

(a)

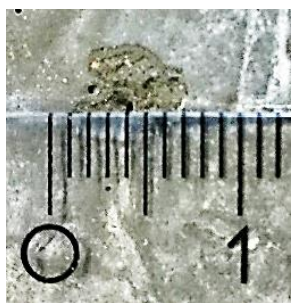

(b)

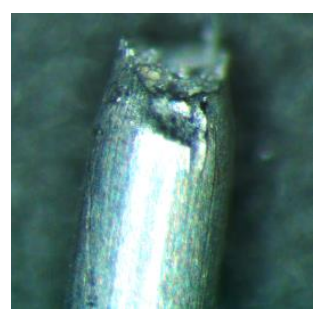

Fig.6 Failures of matrix and fiber: (a) matrix spalling; (b) ruptured fiber

Table 4. Number of fiber ruptured specimens and total tested specimens

\begin{tabular}{ccccc}
\hline Angle $\left({ }^{\circ}\right)$ & 0 & 10 & 20 & 30 \\
\hline H-0.38-10 & 0 out of 5 & 2 out of 7 & 2 out of 7 & 7 out of 10
\end{tabular}




\subsection{Fiber rupture}

253 One common problem for pulling out an inclined fiber is its breakage. In this study, the majority 254 of the $\mathrm{H}-0.38-10$ fibers under $30^{\circ}$ ruptured inside the matrix near the pullout surface. The numbers 255 of specimens experienced fiber rupture are given in Table 4. An example of the ruptured H-0.3825610 fiber is shown in Fig. 6b, in which the irregular break surface and the reduced local cross257 section area due to Poisson effect, i.e. necking, can be clearly observed.

258 During the pullout process, the fiber breaks when the localized strain is higher than its limit 259 value or when the pullout resistance exceeds the ultimate tensile strength of the steel material. As 260 suggested in [25], the yield of the steel fiber is the consequence of inter-crystal slippage in metal 261 caused by atomic-level dislocation movements. In the case of inclined fibers, additional shear 262 stress is imposed on the fiber where it enters the matrix. This additional stress considerably 263 accelerates the inter-crystal slip within the crystal system of the fiber by lowering both its yield 264 and ultimate strength. As a consequence, the inclined fiber would reach the ultimate conditions 265 under a lower applied load. In other words, the fiber rupture load of an inclined fiber is reduced 266 compared to its aligned counterpart, i.e. fiber apparent strength degradation occurs [24]. Since the 267 degradation is more pronounced under larger angle, fibers loaded at a larger inclination angle 268 exhibit a higher possibility to rupture during the pullout process.

\section{$269 \quad 3.3 \quad$ Matrix failure}

270 The pullout behavior of the H-0.9-10 fiber is illustrated in Fig. 7a. For this category, $20^{\circ}$ is the 271 optimum pullout direction to achieve the maximum peak pullout load. The curve of $30^{\circ}$ has a 272 sudden drop at a slip of about $1.8 \mathrm{~mm}$ because all the specimens tested under $30^{\circ}$ have serious 273 matrix failure. Fig. 8 shows examples of a failed matrix specimen and the H-0.9-10 fiber after the 274 test under $30^{\circ}$. As the figure presents, the matrix is cracked from a location near the hooked end 275 and the cracks propagate to the pullout surface, forming a crater inside the concrete. The depth of 276 the crater is approximately the same as the embedded length of the fiber. As can be seen, the H$277 \quad 0.9-10$ fiber is pulled out from the cracked matrix before the hook is straightened, which manifests 278 that the contribution of the hook is not fully utilized. This matrix failure occurs more frequently 279 with the increment of the pullout angle (Table 5).

280 One possible reason that leads to this matrix failure is the larger contact surface between the H281 0.9-10 fiber and the matrix. Considering the larger diameter of the H-0.9-10 fiber, forces can be 
transferred more efficiently from the fiber to the matrix. Furthermore, the prominent anchorage

283 force provided by the hook and the relatively small embedded length in the matrix also conduce 284 to the matrix failure phenomenon. On the one hand, stresses at the bending regions of the hook 285 due to slip shear and shrink-fit initiate the fracture of the matrix, making the matrix near the hook 286 a weak region. On the other hand, the surrounding concrete matrix that covers the hook is too thin 287 to resist the large anchorage force. This inappropriate combination of the large hook size and the 288 small embedded length causes the matrix failure.

289 Increasing the embedded length of the fiber or adding micro fibers in the matrix are two 290 potential methods to prevent the matrix failure. In this study, the former is utilized considering its 291 simplification. The embedded length $l_{\mathrm{e}}$ is increased from $10 \mathrm{~mm}$ to $15 \mathrm{~mm}$, i.e. the H-0.9-15 292 category. With this enlarged $l_{\mathrm{e}}$, only one specimen has the matrix failure problem when it is pulled293 out under $30^{\circ}$, none of the rest specimens encounters this problem. The pullout load-slip 294 relationships for the H-0.9-15 category are plotted in Fig. 7b, in which increments of the peak 295 pullout load are observed with the increase of the angle. Some characteristics that are observed in 296 the H-0.38-10 category, e.g. the pullout slip under the peak load increases while the slope of the 297 pre-peak branch of the curve decreases as the angle improves, still exist and even more obvious in 298 this category. The increment of the slip can be ascribed to the matrix spalling that reduces the 299 embedded length and allows fiber deformation. Moreover, the peak pullout load is also higher 300 compared with that in Fig. 7a, thanks to the longer $l_{\mathrm{e}}$.

Table 5. Number of matrix damaged specimens

\begin{tabular}{ccccc}
\hline Angle $\left(^{\circ}\right)$ & 0 & 10 & 20 & 30 \\
\hline H-0.9-10 & 1 out of 5 & 2 out of 5 & 4 out of 6 & 6 out of 6 \\
\hline
\end{tabular}

302

(a)

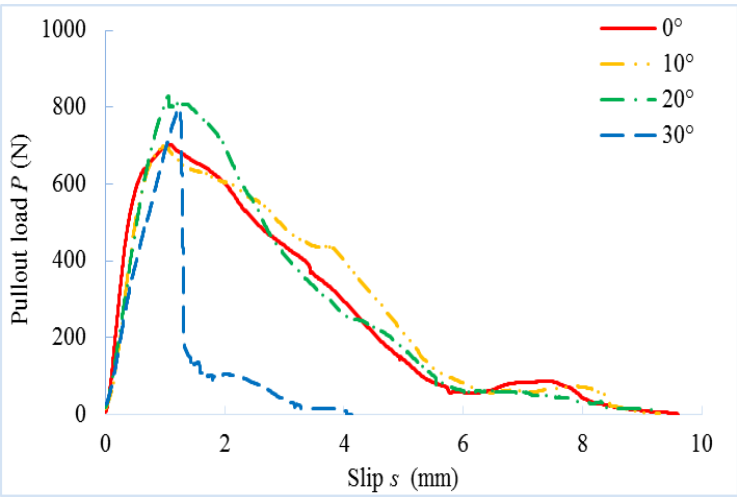

(b)

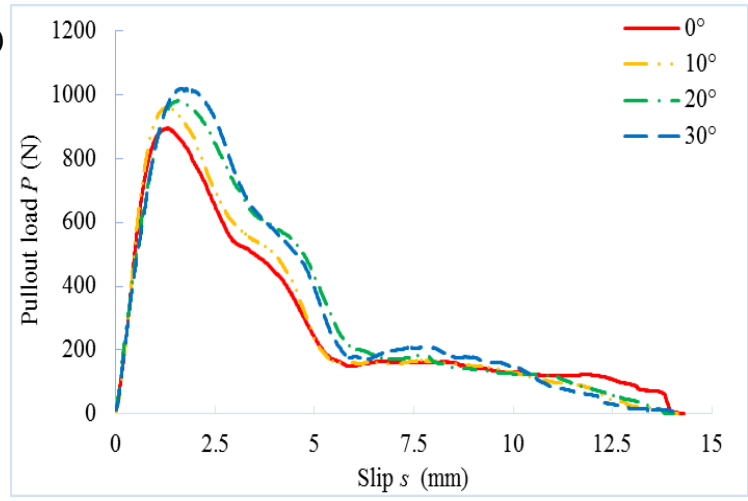

Fig.7 Pullout load-slip curves: (a) H-0.9-10 category; (b) H-0.9-15 category 
305

306

307
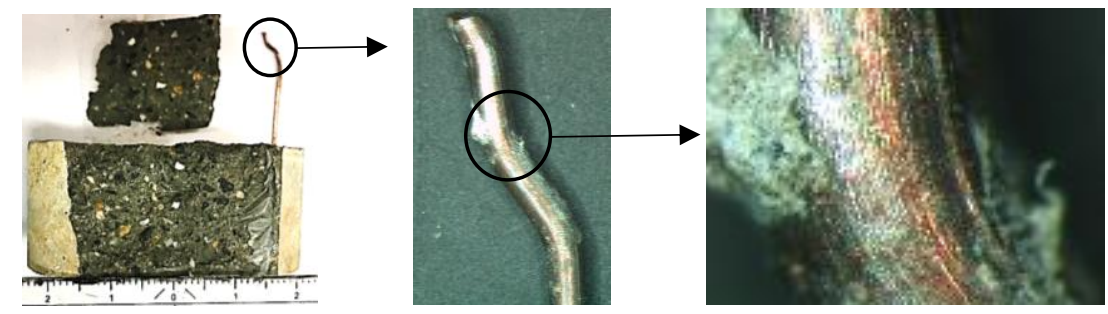

Fig.8 Example of matrix failure and the fiber under $30^{\circ}$ 


\section{Parametric evaluation and mechanism analysis}

$309 \quad 4.1$ Evaluation of parameters for fiber pullout performance

310 To study the influences of the orientation angle on e.g. interfacial bond strength, pullout energy 311 and fiber utilization efficiency, the following mechanical parameters are calculated. The maximum 312 fiber stress $\sigma_{\max }$ is an important parameter to estimate the fiber utilization efficiency and predicts 313 fiber pullout modes, i.e. pullout or rupture. It also gives reference to determine the minimum fiber 314 strength needed to avoid fiber fracture. Assuming the bond strength is constant along the entire 315 fiber embedded length, the equivalent bond strength $\tau_{e q}$ can be defined as the average bond 316 strength based on the pullout energy dissipation, and it is associated with matrix cracking behaviors

$317[15,16]$. Moreover, the maximum bond strength $\tau_{\max }$, related to the peak pullout load, is often 318 used to evaluate the pullout resistances of fibers with different geometries [16]. Equations for 319 calculating these parameters are:

320 Maximum fiber stress: $\sigma_{\max }=\frac{4 P_{\max }}{\pi d^{2}}$

$321 \quad$ Equivalent bond strength: $\tau_{e q}=\frac{2 E}{\pi d L^{2}}$

322 Maximum bond strength: $\tau_{\max }=\frac{P_{\max }}{\pi d L}$

323 where $P_{\max }$ is the peak pullout load (MPa); $E$ is the pullout energy dissipation and defined 324 geometrically by the area below the pullout load-slip curve (N.mm); $d$ is the diameter of the fiber 325 (mm); and $L$ is the actual fiber embedded length obtained from the pullout load-slip curves ( $\mathrm{mm}$ ). 326 Fig .9 presents the angle effect on these mechanical parameters. The pullout energy, equivalent 327 bond strength and maximum bond strength of the H-0.9-10 category under $30^{\circ}$ are not given 328 because of the serious matrix failure making the results incomparable. For the H-0.38-10 category, 329 the listed parameters are almost independent of the inclination angle. This is quite distinct from 330 the H-0.9-15 category, where improving the pullout angle can lead to increases of the parameters. 331 By contrast, for the H-0.9-10 category, $E$ and $\tau_{e q}$ are the highest under $10^{\circ}$, while other parameters 332 achieve their maximum values under $20^{\circ}$. 
(a)

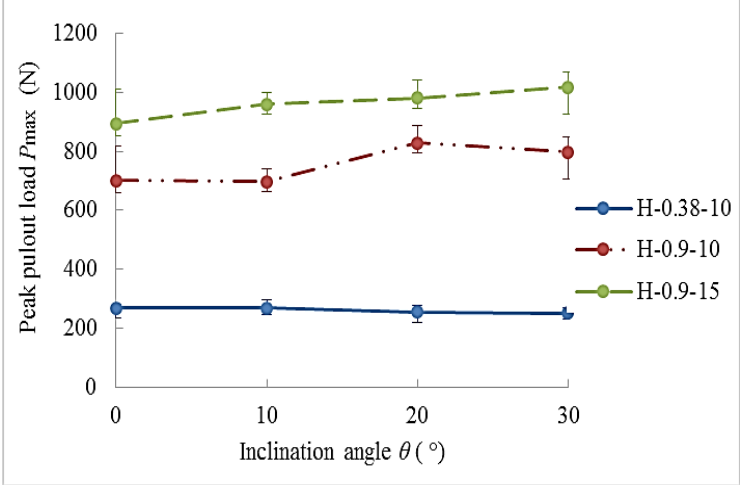

(c)

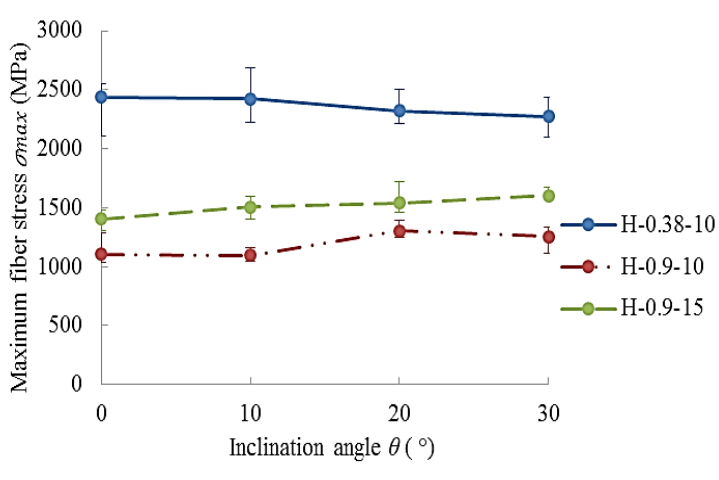

(b)

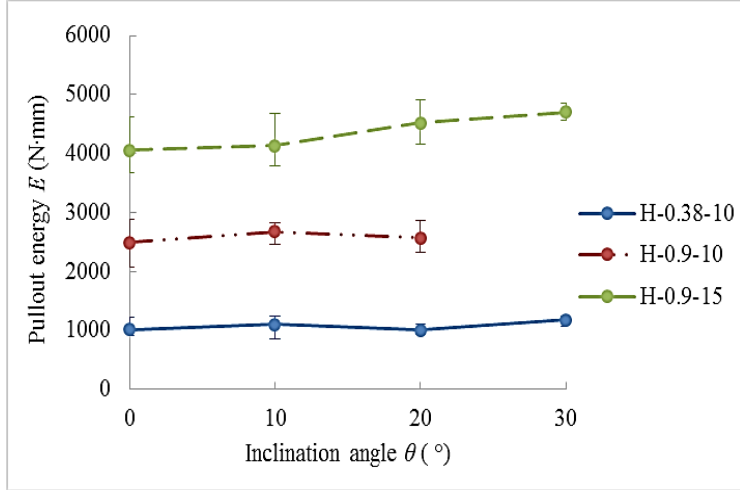

(d)

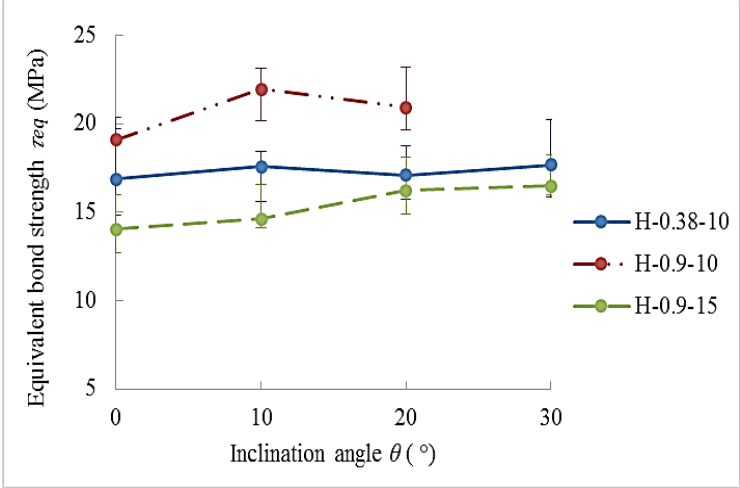

(e)

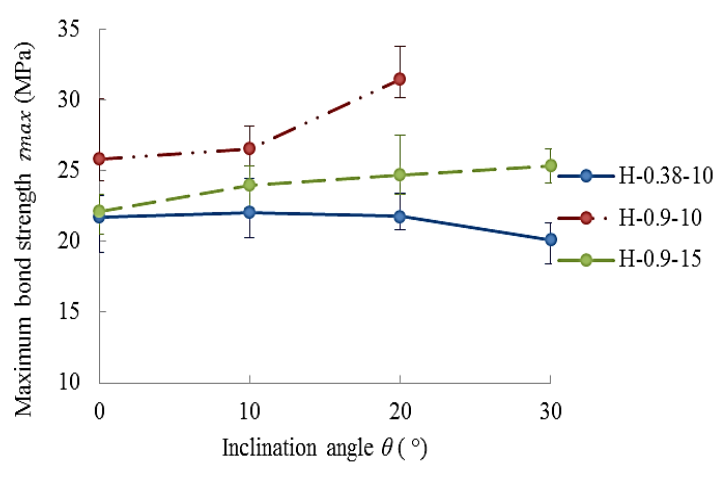

Fig.9 Influences of angle on mechanical parameters: (a) peak pullout load $P_{\max }$; (b) energy dissipation $E$;

(c) Maximum fiber stress $\sigma_{\max }$; (d) Equivalent bond strength $\tau_{e q}$; (e) Maximum bond strength $\tau_{\max }$

In comparing these parameters for the H-0.38-10 and H-0.9-10 fibers, both $P_{\max }$ and $E$ are improved with the larger fiber diameter. Nonetheless, the maximum fiber stress of the H-0.38-10 fiber $\left(\sigma_{\max }=2255 \mathrm{MPa} \sim 2436 \mathrm{MPa}\right)$ is about twice larger than that of the other two categories, and it is close to the yield strength of the steel material $\left(f_{\mathrm{t}}=2600 \mathrm{MPa}\right)$, indicating a higher utilization efficiency of the smaller fiber. This larger $\sigma_{\max }$ also helps to understand the higher fiber breakage occurrence of the H-0.38-10 fiber in the pullout tests. Fig. 9c also plots that for the H- 
0.38-10 category, the aligned fiber or fiber with a small inclination angle achieves the highest fiber efficiency, while for the other two tested categories the fibers are better utilized under $30^{\circ}$.

Overall, in Fig. 9, $\tau_{e q}$ is the highest for the H-0.9-10 category, followed by the H-0.38-10 and H-0.9-15 categories, the ranges of their values are 19 MPa 22 MPa, 16.5 MPa 17.5 MPa and 14 MPa 16.5 MPa, respectively. Since $\tau_{e q}$ is related with matrix cracking behaviors, the higher $\tau_{e q}$ for the H-0.9-10 category is in line with its more frequent matrix failure occurrence during the pullout tests. Moreover, $\tau_{e q}$ in this study with UHPC is much higher than its counterparts with NC and HSC, e.g. the values of $\tau_{e q}$ in [42] with the same fiber as the H-0.38-10 category embedded in $\mathrm{NC}\left(f_{\mathrm{c}}=28 \mathrm{MPa}\right)$ and $\mathrm{HSC}\left(f_{\mathrm{c}}=84 \mathrm{MPa}\right)$ are only 3.5 MPa and 4.7 MPa, respectively. $\tau_{\text {max }}$ is also the highest in the H-0.9-10 category, the values of which are between $26 \mathrm{MPa}$ and $31.5 \mathrm{MPa}$. 355 For the H-0.9-15 category, the maximum bond strength ranges from $22 \mathrm{MPa}$ to $25.5 \mathrm{MPa}$, while for the $\mathrm{H}-0.38-10$ fiber the values are around $21 \mathrm{MPa}$ under the tested angles.

In addition, $P_{\max }$ and $E$ are significantly improved for the hooked end fiber than the straight counterpart. For instance, $P_{\max }$ and $E$ in [43] for aligned straight steel fiber $\left(d=0.2 \mathrm{~mm}, l_{\mathrm{e}}=5 \mathrm{~mm}\right)$ pulled out from ultra-high strength concrete $\left(f_{\mathrm{c}}=110 \mathrm{MPa}\right)$ are only around $45 \mathrm{MPa}$ and $120 \mathrm{~N} \cdot \mathrm{mm}$. This confirms the advantages of hooked end fiber over the straight one and indicates its utilization potential in UHPFRC. Moreover, comparisons between the H-0.9-10 and H-0.9-15 categories demonstrate that increasing the embedded length $l_{\mathrm{e}}$ of the fiber can efficiently enhance $P_{\max }$ and $E$, e.g. they increase $28 \%$ and $65 \%$, respectively, when $l_{\mathrm{e}}$ increases from $10 \mathrm{~mm}$ to $15 \mathrm{~mm}$. However, $\tau_{e q}$ and $\tau_{\text {max }}$ tend to be higher when $l_{\mathrm{e}}$ of the hooked end fiber is shorter, i.e. the averaged $\tau_{e q}$ and $\tau_{\max }$ values of the H-0.9-10 category are approximately $38 \%$ and $18 \%$ higher than those of the $\mathrm{H}-$ 0.9-15 category. This trend is also confirmed by comparing the results of the H-0.38-10 fiber under $0^{\circ}$ with the ones in [15] and [32], which used the same fiber but different embedded lengths. Park et al. [15] analyzed the response of the aligned fiber with $l_{\mathrm{e}}=15 \mathrm{~mm}$ pulled out from UHPC matrix $\left(f_{\mathrm{c}}=180-200 \mathrm{MPa}\right)$ and obtained that the values of $\tau_{e q}$ and $\tau_{\max }$ are $7.5 \mathrm{MPa}$ and $11.7 \mathrm{MPa}$, respectively. In [32], Tai et al. conducted similar tests with $l_{\mathrm{e}}=6 \mathrm{~mm}$ and the UHPC matrix of 150 MPa. In their study, $\tau_{e q}$ and $\tau_{\max }$ under $0^{\circ}$ are $19.8 \mathrm{MPa}$ and $23 \mathrm{MPa}$, respectively. This higher $\tau_{e q}$ and $\tau_{\max }$ with smaller $l_{\mathrm{e}}$ of the hooked end fiber in turn manifests the more prominent 374 
The influences of fiber inclination on the pullout performance are associated with both the snubbing effect and the matrix spalling effect. The phenomenon that the pullout load increases with the increase of the inclination angle is related to the "snubbing effect", owing to snubbing friction forces invoked by fiber bending. As illustrated in Fig. 10a, when a straight fiber is being pulled out from a matrix with an inclination $\theta$ under a force $P$, a snubbing friction force $F$ will be generated by the normal force $N$ and the relative slip between the fiber and matrix. In assumption that the matrix has the same deformation with the bending fiber in the curvature part, the friction system can then be illustrated as a tensioned fiber snubbed to a virtual cylinder [44]. This invoked snubbing friction force only exists in the curvature region and it can promote enhancements of the pullout resistance and the overall composite toughness $[44,25]$. In contrast, the "matrix spalling effect" will lead to the decrease of pullout load with the angle increment. Fiber inclination can cause a stress concentration at the matrix pullout surface, and consequently, local failure of the supporting matrix near the bearing point, i.e. matrix spalling occurs [17]. As the inclination angle increases, the stress concentration is also enhanced, leading to a more considerable portion of the concrete to crush at the pullout surface and a longer freed embedded length, thus a lower pullout 391 load [26].

(a)

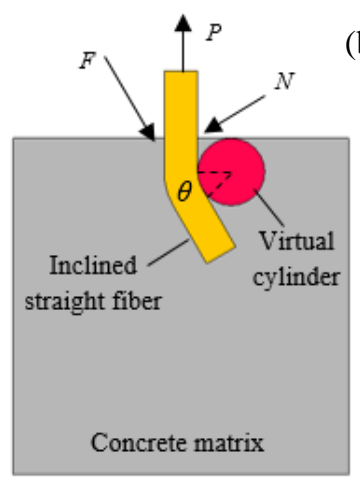

(b)

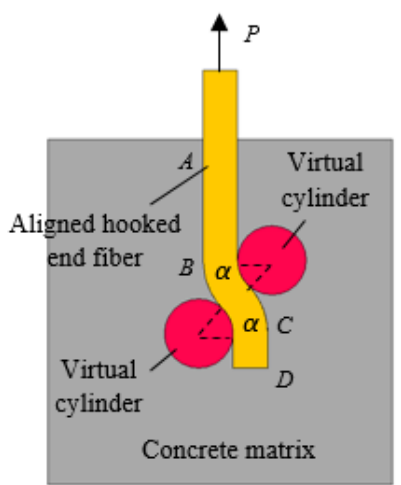

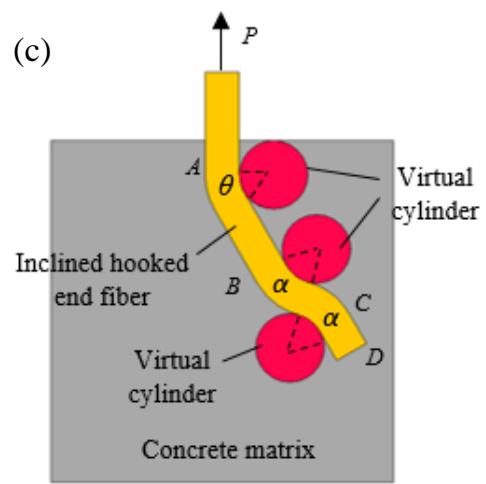

Fig.10 Illustrations of snubbing effect: (a) inclined straight; (b) aligned hooked end; (c) inclined hooked end fibers

394 To study the snubbing effect and the matrix spalling effect, corresponding evaluation 395 coefficients, i.e. snubbing friction coefficient $f$ and spalling coefficient $k$, are calculated. It should 396 be noted that previously proposed equations for calculating $f$ were developed only for straight 397 fibers without mechanical anchorage [17, 26, 28]. This study expands the equations for hooked 398 end fibers and proposes a new analytical model. 
Firstly, a normalized load is defined as the ratio of the peak load to the pullout length at a given angle $\theta$, normalized with the ratio for the pullout angle of $0^{\circ}$ [17]:

$401 \quad P_{n}=\frac{P_{\max , \theta} / L_{\theta}}{P_{\max , 0} / L_{0}}$

402 where $P_{\max , \theta}$ and $P_{\max , 0}$ are the peak pullout loads of a straight or hooked end fiber under $\theta$ and $403 \quad 0^{\circ}(\mathrm{MPa}) ; L_{\theta}$ and $L_{0}$ are the corresponding actual fiber embedded length $(\mathrm{mm})$.

404 As suggested in $[17,26,28,45]$, the following equation is used to represent the snubbing effect 405 on straight fiber:

$406 \quad P_{n, s}=\frac{P_{\max , s, \theta} / L_{\theta}}{P_{\max , s, 0} / L_{0}}=e^{f \theta}$

407 in which $P_{n, s}$ is the normalized load for the straight fiber; $P_{\max , s, \theta}$ and $P_{\max , s, 0}$ are the peak pullout 408 loads of the straight fiber under $\theta$ and $0^{\circ}(\mathrm{MPa})$, respectively.

409 Assuming that the interfacial shear stress is uniform along the embedded fiber and increases 410 gradually with the pullout load until it approaches the interfacial shear strength $\tau_{s}$ [46], together 411 with Eq. (5), $P_{\max , s, \theta}$ and $P_{\max , s, 0}$ can be given as:

$412 \quad P_{\max , s, 0}=\pi d L_{0} \tau_{s}$

$413 P_{\max , s, \theta}=\pi d L_{\theta} \tau_{s} e^{f \theta}$

414 Next, the above equations are expanded for hooked end fibers. The snubbing effects of the 415 hooked end fiber under $0^{\circ}$ and $\theta$ are shown in Figs. $10 \mathrm{~b}$ and c, where $\alpha$ is the angle of the hook; $L_{I J}$ 416 represents the length between point $I$ and $J$, with $I, J=A$ to $D$. As can be observed, even when the 417 hooked end fiber is aligned, snubbing friction forces will be generated during the pullout process 418 because of the curvatures of the hook (the virtual cylinders in Fig. 10b). This denotes similar 419 snubbing effects as the inclined straight fiber in Fig. 10a. Consequently, the peak pullout forces 420 for the hooked end fiber under $0^{\circ}$ and $\theta(\mathrm{MPa})$ can be expressed as Eqs. (8) and (9):

$$
P_{\max , h, 0}=\pi d L_{A B, 0} \tau_{s}+\pi d L_{B C, 0} \tau_{s} e^{f \alpha}+\pi d L_{C D, 0} \tau_{s} e^{f \alpha}=\pi d L_{A B, 0} \tau_{s}+\pi d L_{B D, 0} \tau_{s} e^{f \alpha}
$$

$$
P_{\max , h, \theta}=\pi d L_{A B, \theta} \tau_{s} e^{f \theta}+\pi d L_{B C, \theta} \tau_{s} e^{f \alpha}+\pi d L_{C D, \theta} \tau_{s} e^{f \alpha}=\pi d L_{A B, \theta} \tau_{s} e^{f \theta}+\pi d L_{B D, \theta} \tau_{s} e^{f \alpha}
$$


Substituting Eqs. (8) and (9) into Eq. (4), the normalized load for the hooked end fiber 424 considering the snubbing effect is obtained:

$$
P_{n, h, 1}=\frac{P_{\max , h, \theta} / L_{\theta}}{P_{\max , h, 0} / L_{0}}=\frac{\left(L_{A B, \theta} e^{f \theta}+L_{B D, \theta} e^{f \alpha}\right) L_{0}}{\left(L_{A B, 0}+L_{B D, 0} e^{f \alpha}\right) L_{\theta}}
$$

Moreover, supposing that the pullout load does not reduce in the case of aligned fiber and that 427 the pullout load does not act on the fiber when the load direction is perpendicular to the fiber axial, 428 an equation to account for the spalling effect is presented [26, 28]:

$429 \quad P_{n, h, 2}=(\cos \theta)^{k}$

430 Combining the above two effects, an analytical model for the hooked end fiber is proposed:

$$
P_{n, h}=\frac{P_{\max , h, \theta} / L_{\theta}}{P_{\max , h, 0} / L_{0}}=\frac{\left(L_{A B, \theta} e^{f \theta}+L_{B D, \theta} e^{f \alpha}\right) L_{0}}{\left(L_{A B, 0}+L_{B D, 0} e^{f \alpha}\right) L_{\theta}}(\cos \theta)^{k}
$$

432 The results of the H-0.9-15 category are applied for validating the analytical model, with the 433 angle of the hook $\alpha=45^{\circ}$; hook length $L_{B C}=2.12 \mathrm{~mm}$ and $L_{C D}=2.5 \mathrm{~mm} ; L_{A B}=L-L_{B C} \sin \alpha-$ $434 L_{C D}$. The obtained $f$ and $k$ are 1.25 and 1.0, respectively. Fig. 11 plots the comparison between the 435 test results and the calculated normalized loads for the H-0.9-15 category, as well as for the pullout 436 tests results in [28] with the above obtained $f$ and $k$. The excellent match confirms the validity of 437 the proposed model. It is noted that for the analytical results of [28], $k$ is only used for the 438 inclination case of $45^{\circ}$, in which concrete spalling was observed [28]. Besides, it should be aware 439 that the obtained $f$ and $k$ in this study are distinct from the ones in [26] with straight steel fiber, i.e. $440 f=1.6, k=1.8$. This can be explained by the following reasons. Firstly, the test specimen in [26] 441 includes 32 steel fibers, and the pullout behavior is examined using the average value relative to 442 one fiber. This measure of the pullout load can differ with the result from a single fiber pullout test 443 since it is almost impossible to achieve a uniform load distribution to all the fibers. Moreover, 444 group effect appears in the multiple-fiber tests in [26], which may reduce the fiber efficiency as 445 well as the matrix's capability to resist the bond [19]. Hence, the snubbing friction force has a 446 distinct distribution in the fiber and the spalling of the matrix is also different. 


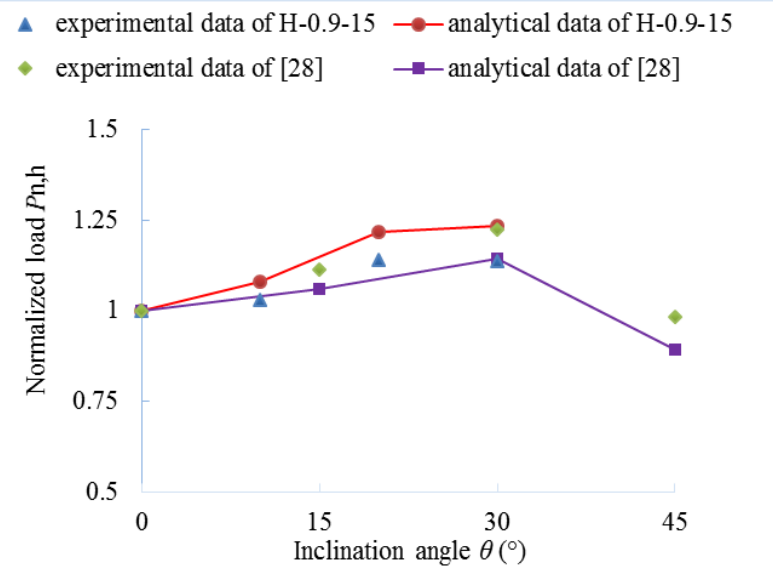

Fig.11 Comparison between experimental data and analytical modelling 


\section{Mesoscopic observations}

450 Mesoscopic observations of the fibers after the pullout tests are performed by using an optical 451 microscope to further investigate the effects of orientation angles on the fiber-matrix bond. The 452 H-0.38-10 and the H-0.9-15 fibers before and after the pullout tests are compared and shown in 453 Figs. 12 and 13. It is evident that the brass coating of the H-0.38-10 fiber is almost completely 454 delaminated from the steel surface after the pullout test. This is different from the H-0.9-15 455 category, in which most of the coated brass still remains on the fiber surface. Thanks to the fine 456 ingredients in the UHPC matrix, only a few longitudinal scratches due to matrix abrasion are 457 observed on the surfaces of the pulled-out fibers. Furthermore, insignificant difference exists 458 between the fiber surfaces under 0 and $30^{\circ}$ : more matrix remnants are observed adhering to the 459 fiber under $30^{\circ}$, e.g. Fig. 12c. These cementitious materials sticking to the fiber accumulate near 460 the fiber end, which in turn are expected to enhance the friction in the post-peak pullout stage. This 461 is in line with the slightly larger post-peak load for the H-0.38-10 fiber under $30^{\circ}$ (see Fig. 6).

(a)

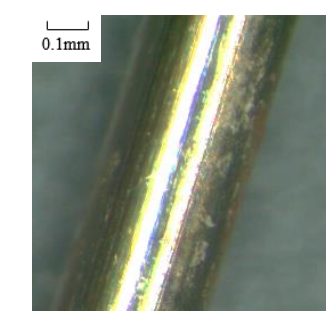

(b)

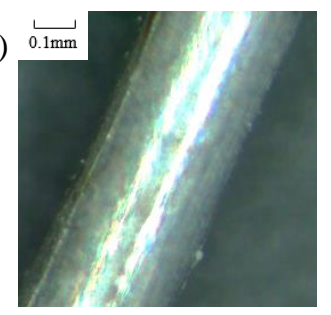

(c)

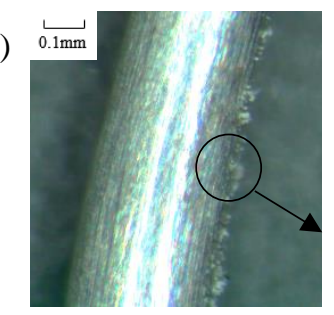

Fig.12 H-0.38-10 fiber under optical microscope observation:

(a) Before pullout test; (b) Pulled out under $0^{\circ}$; (c) Pulled out under $30^{\circ}$

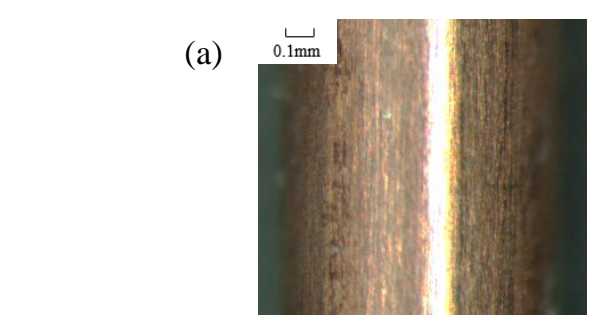

(b)

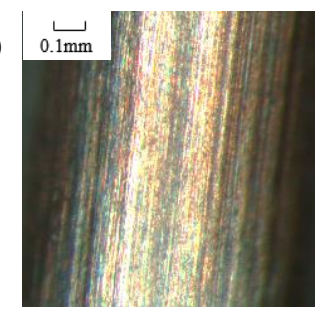

(c)

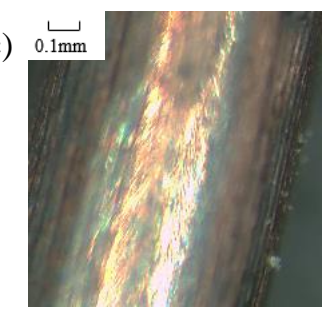

Fig.13 H-0.9-15 fiber under optical microscope observation:
(a) Before pullout test
(b) Pulled out under $0^{\circ}$
(c) Pulled out under $30^{\circ}$

The fiber-matrix interfaces are also observed using SEM. The images of the microstructures around the $\mathrm{H}-0.38-10$ fiber under $0^{\circ}$ and $30^{\circ}$ are presented in Fig. 14. Only a few pores are revealed in the interfacial transition zones (ITZ) around the fiber, implying a dense microstructure and a strong bond between the fiber and the UHPC matrix. This dense ITZ induces the delamination of 
474 the brass coating from the fiber surface during the pullout process and agrees well with the 475 observations in Fig. 12. In addition, the similar ITZ for the 0 and $30^{\circ}$ fibers indicates that the 476 microstructure densification of ITZ is almost not influenced by the inclination angle. According 477 to [30], the physico-chemical bond is one primary component of the fiber-matrix bond, and it is 478 dependent on both the matrix packing density and fiber surface properties. The resemble ITZ 479 density in Fig.14 under different inclination angles reveals a similar physico-chemical bond 480 between the fiber and the matrix, which also helps to explain the similar initial ascending slop of 481 the pullout curves in Fig. 6 that is associated with the fiber-matrix adhesive bonding and debonding 482 process.

(a)
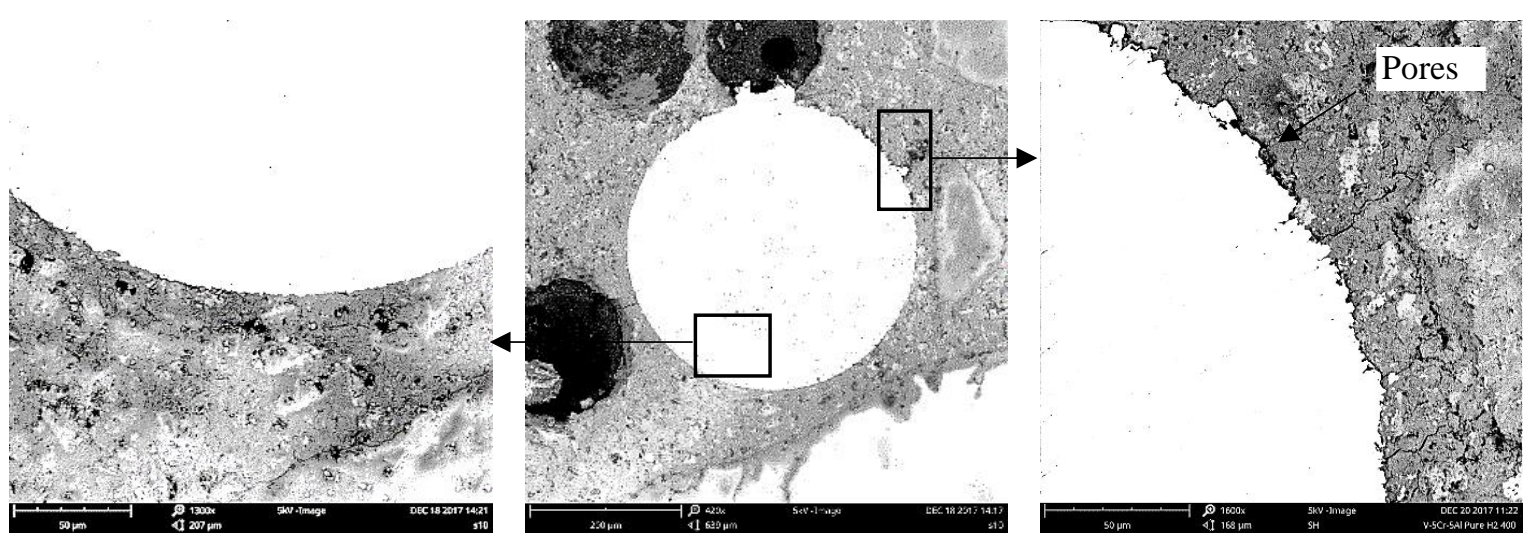

484

(b)
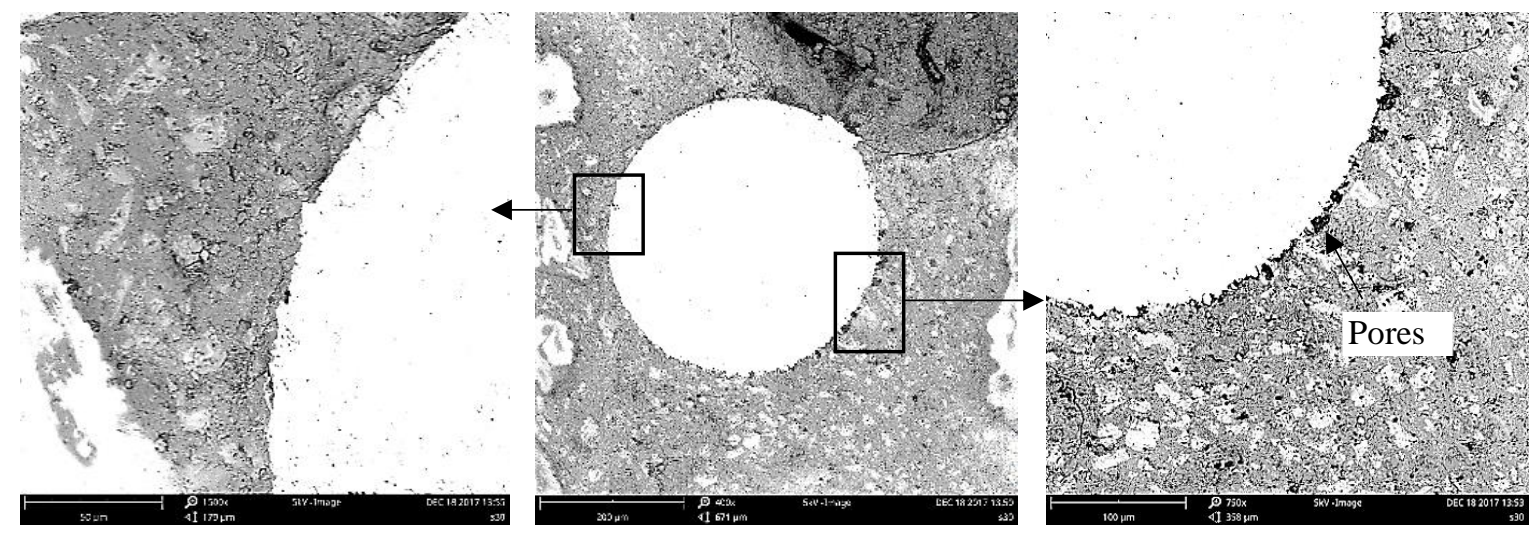

486

Fig.14 SEM images of microstructures around H-0.38-10 fiber: (a) Inclination angle $0^{\circ}$; (b) Inclination angle $30^{\circ}$ 487 


\section{Conclusions}

489 The pullout performances of the hooked end steel fibers embedded in UHPC matrix are 490 systematically investigated in this study. Two types of hooked end fiber with distinct fiber diameter 491 and embedded length are tested and discussed. The effects of inclination angles $\left(0^{\circ}, 10^{\circ}, 20^{\circ}\right.$ and $49230^{\circ}$ ) on the pullout response are analyzed by the single fiber pullout tests, mechanical parameter 493 calculations, mechanisms analysis and mesoscale observations. The following conclusions can be 494 drawn from the study:

495 (1) Due to the strong bond and anchorage in the UHPC matrix, the hooked end fiber with a small 496 diameter, i.e. the H-0.38-10 fiber, ruptures prematurely under a large inclination angle. This 497 is attributed to the fiber apparent strength degradation that increases with orientation. In contrast, the large fiber with an appropriate embedded length, i.e. the H-0.9-15 fiber, shows a complete pullout behavior and exhibits a more ductile response under the tested angles.

(2) Embedded length is an important factor that affects the pullout response of the large hooked end fiber. In the H-0.9-10 category, the relatively small embedded length results in a serious matrix failure problem, which tremendously reduces the energy absorption capacity of the specimen. This phenomenon should be taken into account in design of UHPFRC composites.

(3) For the H-0.38-10 category, the peak pullout loads are similar under various inclination angles, whereas it increases with the angle for the H-0.9-15 category. For the H-0.9-10 category, the optimum inclination angle to achieve the maximum pullout resistance is around $20^{\circ}$.

(4) Regarding fiber efficiency, the hooked end fiber with a small diameter, i.e. the H-0.38-10 fiber, has a higher utilization level and it is the highest under a pullout angle of $0^{\circ}$. The utilization efficiency for the H-0.9-10 and H-0.9-15 categories are approximately half of the H-0.38-10 category, and both of them reach the maximum values under $30^{\circ}$.

(5) To effectively evaluate the combined effects of snubbing and matrix spalling, a new analytical model for hooked end fibers are proposed. It shows clearly that the analytical model provides a reasonable agreement with the experimental data.

(6) The SEM images of the fiber-matrix interface confirm the dense microstructure of the ITZ in the designed UHPC matrix. It demonstrates that the fiber inclination do not have much 


\section{$519 \quad 7 \quad$ Acknowledgements}

520 This research was carried out under the funding of China Scholarship Council (No. 521 201503170258) and Eindhoven University of Technology. Mr. Verhagen is thanked for the 522 experimental supports. Furthermore, the authors wish to express their gratitude to the following 523 sponsors of the Building Materials research group at TU Eindhoven: Rijkswaterstaat Grote 524 Projecten en Onderhoud; Graniet-Import Benelux; Kijlstra Betonmortel; Struyk Verwo; Attero; 525 Enci; Rijkswaterstaat Zee en Delta-District Noord; Van Gansewinkel Minerals; BTE; V.d. Bosch 526 Beton; Selor; GMB; Icopal; BN International; Eltomation, Knuaf Gips; Hess AAC Systems; 527 Kronos; Joma; CRH Europe Sustainable Concrete Centre; Cement \& Beton Centrum; Heros; 528 Inashco; Keim; Sirius International; Boskalis; NNERGY; Millvision; Sappi and Studio Roex (in 529 chronological order of joining). 


\section{References}

532 [1] Yu R. (2015). Development of sustainable protective Ultra-High Performance Fiber Reinforced Concrete (UHPFRC)-Design, assessment and modeling. PhD thesis. Eindhoven University of Technology, Eindhoven, the Netherlands.

[2] Rossi P. (2013). Influence of fiber geometry and matrix maturity on the mechanical performance of ultra-high-performance cement-based composites. Cement and Concrete Composites 37: 246-248.

[3] Yu R., Spiesz P.R., Brouwers H.J.H. (2014). Static properties and impact resistance of a green Ultra-High Performance Hybrid Fiber Reinforced Concrete (UHPHFRC): experiments and modeling. Construction and Building Materials 68: 158-171.

[4] Yu R., Spiesz P.R., Brouwers H.J.H. (2014). Mix design and properties assessment of UltraHigh-Performance Fiber Reinforced Concrete (UHPFRC). Cement and Concrete Research 56: 29-39.

[5] Tran N.T., Tran T.K., Jeon J.K., Park J.K., Kim D.J. (2016). Fracture energy of ultra-highperformance fiber-reinforced concrete at high strain rates. Cement and Concrete Research 79: $169-184$.

[6] Hassan A.M.T., Jones S.W., Mahmud G.H. (2012). Experimental test methods to determine the uniaxial tensile and compressive behavior of Ultra-high Performance Fiber Reinforced Concrete (UHPFRC). Construction and Building Materials 37: 874-882.

[7] Thomas J., Ramaswamy A. (2007). Mechanical Properties of Steel Fiber-Reinforced Concrete. ASCE Journal of Materials in Civil Engineering 19(5): 385-392.

[8] Johnston C.D. (2001). Fiber-Reinforced Cements and Concrete. Gordon and Breach Science Publishers, Ottawa, Canada.

[9] Tran N.T., Tran T.K., Kim D.J. (2015). High rate response of ultra-high-performance fiber reinforced concretes under direct tension. Cement and Concrete Research 69:72-87.

[10] Wille K., Naaman A. E. (2010). Bond Stress-Slip Behavior Of Steel Fibers Embedded In Ultra High Performance Concrete. Proceedings of 18th European conference on fracture and damage of advanced fiber-reinforced cement-based materials, 99-111.

[11] Abdallah S., Fan M.Z., Zhou X.M. (2017). Pullout Behavior of Hooked-end Steel Fibers Embedded in Ultra-high Performance Mortar with Various W/B Ratios. International Journal of Concrete Structures and Materials 11(2): 301-313.

[12] Markovic I. (2006). High-Performance Hybrid-Fiber Concrete - Development and Utilisation. PhD thesis. Technische Universiteit Delft, Delft, the Netherlands.

[13] Orange G., Acker P., Vernet C. (1999). A new generation of UHP concrete: DUCTAL damage resistance and micromechanical analysis. Proceedings of RILEM- High Performance Fiber Reinforced Cement Composites, 101-111.

[14] Kim J.J., Kim D.J., Kang S.T., Lee J.H. (2012). Influence of sand to coarse aggregate ratio on the interfacial bond strength of steel fibers in concrete for nuclear power plant. Nuclear Engineering and Design 252: 1- 10. 
[15] Park S.H., Ryu G.S., Koh K.T., Kim D.J. (2014). Effect of shrinkage reducing agent on pullout resistance of high-strength steel fibers embedded in ultra-high-performance concrete. Cement and Concrete Composites 49: 59-69.

[16] Yoo D.Y., Park J.J., Kim S.W. (2017). Fiber pullout behavior of HPFRCC: Effects of matrix strength and fiber type. Composite Structures 174: 263-276.

[17] Li V.C., Wang Y., Backer S. (1990). Effect of inclining angle, bundling and surface treatment on synthetic fibre pull-out from a cement matrix. Composites 21(2): 132-140.

[18] Wille K., Naaman A.E. (2012). Effect of ultra-high-performance concrete on pullout behavior of high-strength brass-coated straight steel fibers. Materials Journal 110 (4): 451462.

[19] Wille K., Naaman A.E. (2012). Pullout behavior of high-strength steel fibers embedded in ultra-high-performance concrete. Materials Journal 109 (46): 479-488.

[20] Wille K., Naaman A.E. (2012). Ultra-high performance concrete and fiber reinforced concrete: achieving strength and ductility without heat curing. Materials and Structures 45 (3): 309-324.

[21] Yoo D.Y., Lee J.H., Yoon Y.S. (2013). Effect of fiber content on mechanical and fracture properties of ultra high performance fiber reinforced cementitious composites. Composite Structures 106: 742-753.

[22] Laranjeira F., Molins C., Aguado A. (2010). Predicting the pullout response of inclined hooked steel fibers. Cement and Concrete Research 40: 1471-1487.

[23] Isla F., Ruano G., Luccioni B. (2015). Analysis of steel fibers pull-out. Experimental study. Construction and Building Materials 100: 183-193.

[24] Zhang J., Li V.C. (2002). Effect of inclination angle on fiber rupture load in fiber reinforced cementitious composites. Composites Science and Technology 62: 775-781.

[25] Robins P., Austin S., Jones P. (2002). Pull-out behaviour of hooked steel fibres. Materials and Structures 35: 434-442.

[26] Lee Y., Kang S.T., Kim J.K. (2010). Pullout behavior of inclined steel fiber in an ultra-high strength cementitious matrix. Construction and Building Materials 24: 2030-2041.

[27] Xu M., Hallinan B., Wille K. (2016). Effect of loading rates on pullout behavior of high strength steel fibers embedded in ultra-high performance concrete. Cement and Concrete Composites 49: 59-69.

[28] Tai Y.S., El-Tawil S. (2017). High loading-rate pullout behavior of inclined deformed steel fibers embedded in ultra-high performance concrete. Construction and Building Materials 148: 204-218.

[29] Yoo D.Y., Banthia N. (2016). Mechanical properties of ultra-high-performance fiberreinforced concrete: A review. Cement and Concrete Composites 73: 267-280.

[30] Wille K. (2012). Concrete strength dependent pull-out behavior of deformed steel fibers. 8th RILEM International Symposium on Fiber Reinforced Concrete: challenges and opportunities, 123-135. 
[31] Peng Y., Wu H., Fang Q., Liu J.Z., Gong Z.M. (2016).Impact resistance of basalt aggregated UHP-SFRC/fabric composite panel against small caliber arm. International Journal of Impact Engineering 88: 201-213.

[32] Tai Y.S., S. El-Tawil, T.H. Chung. (2016). Performance of deformed steel fibers embedded in ultra-high performance concrete subjected to various pullout rates. Cement and Concrete Research 89: 1-13.

[33] Liu J.Z., Han F.Y., Cui G., Zhang Q.Q., Lv J., Zhang L.H., Yang Z.Q. (2016). Combined effect of coarse aggregate and fiber on tensile behavior of ultra-high performance concrete. Construction and Building Materials 121: 310-318

[34] Kim D.J., Park S. H., Ryu G. S., Koh K. T. (2011). Comparative flexural behavior of Hybrid Ultra High Performance Fiber Reinforced Concrete with different macro fibers. Construction and Building Materials 25: 4144-4155.

[35] Yoo D.Y., Kim S., Park G.J., Park J.J., Kim S.W. (2017). Effects of fiber shape, aspect ratio, and volume fraction on flexural behavior of ultra-high-performance fiber-reinforced cement composites. Composite Structures 174: 375-388.

[36] Wille K., Naaman A.E., El-Tawil S., Parra-Montesinos G.J. (2012). Ultra-high performance concrete and fiber reinforced concrete: achieving strength and ductility without heat curing. Materials and Structures 45: 309-324.

[37] Wille K., Kim D.J., Naaman A.E. (2011). Strain-hardening UHP-FRC with low fiber contents, Material Structure 44: 583-598.

[38] Park S.H., Kim D.J., Ryu G.S., Koh K.T. (2012). Tensile behavior of ultra high performance hybrid fiber reinforced concrete. Cement and Concrete Composites 34: 172-184.

[39] Wu Z., Shi C., He W. (2016). Effects of steel fiber content and shape on mechanical properties of ultra high performance concrete. Construction and Building Materials 103: 814.

[40] Li PP, Yu QL, Brouwers HJH. (2018). Effect of coarse basalt aggregates on the properties of Ultra-high Performance Concrete (UHPC). Construction and Building Materials 170: 649-659.

[41] Banthia N. Trottier J.F. (1994). Concrete reinforced with deformed steel fibers, part I: bondslip mechanisms. ACI Materials Journal 91(5): 435-446.

[42] Kim D.J., El-Tawil S., Naaman A.E. (2008). Loading rate effect on pullout behavior of deformed steel fibers. ACI Materials Journal 105(6): 576-584.

[43] Wu Z.M., Shi C.J., Khayat K.H. (2016). Influence of silica fume content on microstructure development and bond to steel fiber in ultra-high strength cement-based materials (UHSC). Cement and Concrete Composites 71: 97-109.

[44] Li V.C., Wang Y., Backer S. (1991). A micromechanical model of tension-softening and bridging toughening of short random fiber reinforced brittle matrix composites. Journal of the Mechanics and Physics of Solids 39(5): 607-625. 
647 [45] Yang E.H., Wang S.X., Yang Y.Z., Li V.C. (2008). Fiber-bridging constitutive law of engineered cementitious composites. Journal of Advanced Concrete Technology 6(1): 181193.

[46] Fu S.Y., Zhou B.L., Lung C.W. (1992). On the pull-out of fibers with fractal-tree structure 652 and the inference of strength and fracture toughness of composites. Smart Materials and Structures 1: 18-185. 